\title{
DRUŠTVENE PROMENE I OBRAZOVANJE - PROFESIONALNI I RODNI IDENTITET NOVINARKI U VOJVODINI ${ }^{1}$
}

\begin{abstract}
Apstrakt: Ideja rada je da pokaže na koji način formalno i neformalno obrazovanje utiče na formiranje profesionalnog identiteta novinarki, u kakvoj su relaciji profesionalni i rodni identitet, kao i koliko obrazovanje može da doprinese ravnopravnijem položaju žene u društvu. Pretpostavka je da formalno akademsko obrazovanje ima značajan uticaj na kvalitetan profesionalni rad novinarki, ali nedovoljno za rodno osetljiv pristup. Značaj neformalnog obrazovanja posebno dobija na važnosti poslednje dve decenije kada dolazi do tehničkotehnološkog napretka koji se najviše reflektuje upravo u sferi medija, kroz proces digitalizacije i stvaranjem novih platformi distribucije medijskog sadržaja. Istraživanje je rađeno metodom usmene životne priče (oral history) koji predstavlja jedan od mogućih načina beleženja, analiziranja i interpretiranja iskustva žena kao svedočenja o društvenim okolnostima u određenom vremenskom periodu. Uzimajući u obzir multietničku i multikulturalnu specifičnost Vojvodine za uzorak je odabrano osam novinarki iz medija koji izveštavaju na jezicima različitih nacionalnih zajednica, različitog profesionalnog iskustva i društvenog aktivizma.
\end{abstract}

Ključne reči: obrazovanje, novinarke, rodni identitet, profesionalni identitet, društvene promene.

\section{UVODNE NAPOMENE}

Većina istraživanja koja se bave pitanjima roda i medija fokusirana je na reprezentaciju žene u medijima, dok je mali broj onih koji se bave položajem žena zaposlenih u medijima, njihovim obrazovanjem i društvenim statusom novinarki. Obrazovanje žena u većem broju u drugoj polovini 20.veka značilo je ulazak ove društvene grupe u institucije i profesije koje su do tada bile organizovane po patrijarhalnom modelu kojim su dominirali muškarci. Novinarstvo je važilo za pretežno mušku profesiju. Jedan od važnijih aspekata feminističke kulturne politike bilo je povećanje broja žena u medijima uopšte, posebno na rukovodećim

\footnotetext{
Smiljana Milinkov, smilinkova@gmail.com

U radu je predstavljen deo šireg istraživanja rađenog za potrebe doktorske disertacije „Formalno i neformalno obrazovanje i profesionalni status novinarki u Vojvodini-rodna perspektiva" koju je Senat Univerziteta u Novom sadu odobrio 31.03.2014.
} 
pozicijama (prema Gill 2007:36). Žene u novinarsku profesiju ulaze kao druge, a kako istraživanja pokazuju, danas, bez obzira na veći broj žena u medijima, upravljačke strukture i dalje pripadaju muškarcima. Kada je reč o rodnoj strukturi zaposlenih u medijima u Srbiji ne postoje baze podataka, niti statistički podaci, međutim, na osnovu pojedinih istraživanja i evidencije novinarskih udruženja može se konstatovati da žene čine većinu kada je reč o novinarskoj profesiji, dok su muškarci i dalje u većem broju vlasnici, direktori i menadžeri u medijima. Ove navode ilustruju i rezultati istraživanja "Profesija na raskršću-novinarstvo na pragu informacionog društva 2010-2011." Fakulteta političkih nauka u Beogradu. Polna struktura ispitanika pokazuje da su žene brojnije u novinarskom poslu ( $52 \%$ novinarki, $43 \%$ novinara i pet procenata bez odgovora na pitanje o polu), dok na rukovodećim strukturama u medijima (vlasnici i menadžeri) dominiraju muškarci (59\% muškaraca, 33\% žena i osam procenata bez odgovora). Anketirani novinari su kao najveće probleme profesije u Srbiji naveli slabe plate (20\% ispitanika), nizak nivo profesionalizma i nepoznavanje novinarske etike (17\%), a potom (16\%) nizak društveni ugled i status profesije (Milivojević 2011:120). Istraživanje o položaju novinarki koje su 2008. godine sprovele članice Sekcije žena Nezavisnog udruženja novinara Srbije (NUNS), pokazuje da je ženama u novinarstvu najveći problem usklađivanje privatnog života i profesije bez utvrđenog radnog vremena. „Međutim vremenom a posebno ukoliko su postigle uspeh u profesiji žene se naprosto trude da zaborave na kakve su sve prepreke nailazile i jedne su od najglasnijih zastupnica teze da o rodnoj ravnopravnosti nema šta da se priča" (Skrozza 2008:25). Novinarke relativno rano, već u tridesetim godinama života, napuštaju karijeru kako bi se posvetile deci jer je zbog prirode ove profesije, teško istovremeno podizati decu i graditi karijeru. U medijima se ženama prepušta novinarstvo nižeg statusa kao što su zabavni program na televiziji i časopisi (prema De Berg 2007:167). Bez obzira na povećanje broja žena u medijima, problem njihove prezentacije ostao je i dalje kompleksan, jer se ne može povući paralela između učešća u medijima i boljeg „,imidža“ u medijskom sadržaju (prema Gill 2007:36).

$\mathrm{Na}$ osnovu navedenih istraživanja može se konstatovati da se o položaju žena u medijima govori sa dva stanovišta, roda i (ili) profesije. Rodna perspektiva otvara problem patrijarhalnog shvatanja uloge žene svedene samo na njenu reproduktivnu funkciju, što se ogleda u konstataciji da žene rano napuštaju novinarstva radi majčinstva i porodice (prema De Berg:2007). Profesionalna perspektiva otvara problem samopotiskivanja ženskog identiteta u smislu negacije problema rodne neravnopravnosti u novinarstvu (prema Skroza 2008).

Cilj rada je da na osnovu metoda usmenih životnih priča (oral history) pokaže na koji način formalno i neformalno obrazovanje utiče na formiranje profesionalnog i rodnog identiteta novinarki, kao i koliko obrazovanje može da doprinese promeni stereotipne predstave žene u medijskom sadržaju. U 21.veku nedostaju relevantni različiti podaci, ali na osnovu nekoliko do sada objavljenih može se zaključiti da je odnos roda i obrazovanja u novinarskoj profesiji kompleksan i da se više komponenti mora uzeti u obzir kada se o ovoj profesiji daje istorijska perspektiva 
kao i procene današnjeg trenutka. Stoga su u istraživanju kao parametri praćeni stepen obrazovanja, važnost neformalnog obrazovanja za novinarsku profesiju, napredovanje u karijeri, društveno priznanje, kao I odnos na relaciji profesijamaterinstvo-porodica.

\section{TEORIJSKO-METODOLOŠKI OKVIR}

Prema teoretičarki Lisbet van Zonen (Liesbet van Zoonen) feminističke teorije koje se bave medijima mogu se klasifikovati na: teorije radikalnog feminizma koje se najviše interesuju za pornografiju, teorije liberalnog feminizma koje se bave stereotipima i rodnim ulogama žena i teorijama marksističkog (socijalističkog) feminizma koje se bave ideologijom i klasom u odnosu na na rod (Van Zoonen 2004:114). Problem drugosti i položaja žene kao Druge otvara Simon de Bovoar (Simone de Beauvoir) knjigom Drugi pol na čemu se i zasniva egzistencijalistički feminizam jer i pored pomaka u građanskim pravima, ženski rod je i dalje podređen, inferioran, žena se definiše kao Drugi-Druga u odnosu na muškarca (Bahovec 2011:125). Žene u novinarsku profesiju ulaze kao druge i bez obzira na veći broj žena u medijima poslednjih decenija muškarci i dalje imaju profesionalnu i političku moć. Novinarke pripadnice manjinskih nacionalnih zajednica su dvostruko drugo u odnosu na novinarke iz većinske zajednice i muške kolege $u$ sopstvenoj zajednici. Problem ukrštanja rodnih razlika sa svim ostalim razlikamaetničkim, klasnim, rasnim i statusnim, kao i dalji uticaj patrijarhalnog diskursa na univerzalističke pretpostavke mišljenja, saznanja, političkog i etičkog delovanja postavlja postmoderni feminizam. Postmodernost podrazumeva kritičko preispitivanje i dovođenje u pitanje modernih formi mišljenja i društvene organizacije. U tom smislu jedna od osnovnih pretpostavki postmodernizma jeste da je realnost diskurzivno konstruisana. Neke savremene feminističke teoretičarke poput Džudit Batler (Batler 2001; Batler 2010) ali i drugi postmoderni teoretičari Mišel Fuko (Fuko 2006), Žak Derida (Derida 2000), polaze od pretpostavke da je subjekat već proizvod diskursa, jezika, istorije, kulture, i politike. To znači da je subjekat proizveden odnosom sa drugim, shvaćenim kao „drugi jezik“, druga kultura, druga osoba- drugi pol (prema Blagojević, Lončarević 2001:204).

Metod usmene životne priče (oral history) predstavlja jedan od mogućih metoda beleženja, analiziranja i interpretiranja iskustva žena kao svedočenja o društvenim, političkim i profesionalnim okolnostima $\mathrm{u}$ datom vremenskom periodu $\mathrm{u}$ određenom geografskom regionu. U domaćoj literaturi beležena su sećanja i svedočenja pojedinačnih žena, javnih ličnosti međutim tek 1998. projektom „Životne priče Vojvođanki“ Ženskih studija i istraživanja u Novom Sadu počinje beleženje iskustava nepoznatih žena, jer ,za patrijahalni pristup u kojem se žena suočava sa dominacijom muškaraca u društvu, svaka životna priča žene je za istraživačicu jedinstvena,neponovljiva i istinita. Prema Mirni Velčić, male lične priče su deo prostora na kojem se etnografski diskurs otvara svakodnevnim komunikacijskim modelima pripovedanja, i na taj način daje doprinos naučnom 
diskursu „U tom smislu se lično pripovedanje više ne predstavlja kao suprotnost Znanju“(Velčić 1991:166).

Izučavanje obrazovanja, društvenog položaja i profesionalnog statusa novinarki iz perspektive sopstvenog iskustva u našem društvu nema dugu tradiciju. Iskustva pojedinih novinarki mogu se pronaći u publikacijama koje su objavljene kao rezultat višegodišnjeg projekta "Životne priče žena iz manjinskih grupa" novosadskih Ženskih studija i istraživanja, kojim je rukovodila profesorka Svenka Savić ali je primaran kriterijum pri odabiru sagovornica bila etnička pripadnost a ne profesija kojom se bave. U Srbiji nema istraživanja koja koriste etnografske metode posmatranja i učestvovanja u prikupljanju podataka o različitim aspektima obrazovnog sistema. Takođe ne postoje kvalitativni podaci o rodnim odnosima u obrazovnom sistemu u u Srbiji (prema Popović, Duhaček 2011:316).

Analiza položaja žena u novinarstvu u Vojvodini u drugoj polovini 20. i početkom 21. veka mogla bi doprineti studijama roda i društvenoj nauci, a na osnovu životnih priča vojvođanskih novinarki može se rasvetliti na koji način različite društvene kategorije, a pre svega formalno i neformalno obrazovanje, utiču na formiranje rodnog identiteta i u kakvoj je on relaciji sa profesionalnim identitetom.

\section{OBRAZOVANJE NOVINARKI U SRBIJI}

U patrijarhalnom društvu, kakvo je poput većine evropskih bilo i srpsko u 19. veku, dominiralo je negativno mišljenje o umnim kapacitetima žena. „Muškarci u Srbiji, vladari i političari, upravnici vodećih institucija, lekari, urednici kulturnih listova, književnici i drugi intelektualci, većinom obrazovani na inostranim univerzitetima, nisu odobravali aktivnosti „mislećih ženskinja“(Tomić 2014:42). Presudni uticaj na ostvarivanje prava žena na obrazovanje, profesiju, zaposlenje i ekonomsku nezavisnost imali su feministički pokreti koji su ojačali u drugoj polovini 19.veka. Obrazovanje je bilo jedno od prvih ljudskih prava koje su žene izvojevale, znatno pre političkih i ekonomskih (Trgovčević 2014:58). Ipak žene su u tadašnjem jugoslovenskom društvu bile Druge u pogledu prava na obrazovanje sve do kraja Drugog svetskog rata, a do školovanja žena u većem broju dolazi tek u drugoj polovini 20. veka.

Skoro čitav vek ranije, početkom emancipacije žena, beleže se i prve aktivnosti novinarki u Srbiji, a Julijana Radivojević je bila prva novinarka i urednica časopisa na srpskom jeziku koja je uređivala almanah Talije (prema Stojaković 2012:25). U drugoj polovini 19. veka u Srbiji je postojalo više listova namenjenih ženama čiji su urednici bili muškarci. Početkom 20. veka u Vojvodini Milica Tomić objavljuje mesečni časopis Žena (1911-1914). Kao prva novinarka u Srbiji koja je pisala za informativno-politički list pominje se Maga Magazinović koja 1905. u Politici (samo godinu dana nakon osnivanja tog dnevnog lista) objavljujuje članak pod naslovom „Obrazovanje ženskinja u Srbiji“ (prema Zaharijević, Lončarević 2008:432). Nakon Drugog svetskog rata, ideološki, zakonski i delimično ekonomski 
socijalistička Jugoslavija podržava emancipaciju žena (Vilenica 2013:16), ideološki plan prenošen je putem štampanih medija, a ulogu prenošenja poruka ženama preuzimala je AFŽ (Antifašistički front žena) štampa. Nakon nominalnog izjednačavanja prava žena i muškaraca, emancipacije žena i uzleta feminističke štampe u prvim godinama nakon Drugog svetskog rata, pedesetih godina 20. veka, uvođenjem sistema samoupravljanja i gašenja AFŽ-a započinje proces retradicionalizacije društva koji kulminira 90-tih godina kada dolazi do transformacije socijalističkog društva u društvo kojim dominira nacionalni sistem vrednosti sa patrijarhalnim okvirom koji dovodi do ratova i masovnog osiromašenja stanovništva. Nove nacionalne ideologije podvode interese žena interesima nacije, žene se vraćaju tradicionalnoj ulozi majke i domaćice, a ženska radna snaga izložena je dekvalifikaciji i deprofesionalizaciji. S obzirom da je Srbija devedesetih godina godina bila društvo sa razorenim bazičnim institucijama (država, privreda, kultura) i „urušenim“ tradicionalnim formama obrazovanja, žene, pokušavajući da poprave svoj položaj, počinju da se angažuju u nevladinim organizacijama i da kroz ,ženske grupe“ putem neformalnog obrazovanja šire anti-militarističke, feminističke i antiseksističke ideje (prema Veselić, Popović 337-338). Kao odgovor na dominaciju državnih medija javnim prostorom, u Srbiji se između 1991. i 2000. godine osniva najveći broj medija. (Matović 2013: 1998). Motivi njihovog nastanka $\mathrm{u}$ to vreme nisu bili komercijalne već profesionalne prirode (Milivojević 2012; Matović 2012), odnosno reč je o medijima koji su predstavljali suprotnost dominatnim režimskim medijima koji su podržavali nacionalističku politiku tadašnje vlasti. Upravo u tim medijima otvara se prostor za vidljivost ženskih organizacija i podršku njihovim aktivnostima protiv rata, mržnje, nasilja, diskriminacije drugog i drugačijeg (neke od njih su Žene u crnom, Centar za antiratnu akciju, Helsinški odbor za ljudska prava, Ženske studije), a novinari i novinarke imaju priliku da pohađaju seminare, predavanja, konferencije, radionice i ostale oblike neformalnog obrazovanja kao vid nadgradnje prethodnog formalnog obrazovanja i profesionalnog iskustva. Pod neformalnim obrazovanjem podrazumeva se organizovana i sistematska obrazovna aktivnost koja se realizuje van struktura formalnog sistema obrazovanja koja je usmerena na osposobljavanje odraslih za rad, socijalne aktivnosti i privatan život (prema Veselić, Popović 332). Rodno osetljiv jezik, kao jedan od pokazatelja položaja žene u društvu, krajem devedesetih godina mogao se čuti u svega nekoliko medija u Srbiji većinom u okviru ANEM-a (Asocijacije nezavisnih elektronskih medija), kao što su B92 i Radio 021, što može ukazati i na spremnost uredništva i novinara da prihvate $\mathrm{i}$ promovišu promene u društvu učestvujući u neformalnom obrazovanju jer rodna ravnopravnost nije bila deo tadašnjeg zvaničnog, niti državnog niti obrazovnog diskursa. Početkom novog milenijuma, rušenjem režima Slobodana Miloševića u Srbiji nastupa period tranzicije, koji sa jedne strane donosi neophodne zakonske mehanizme za zaštitu rodne ravnopravnosti, dok je sa druge strane i dalje prisutan obrazac koji afirmiše patrijarhalnu i tradicionalističku ulogu žene koja ograničava njeno profesionalno i društveno angažovano delovanje, što potvrđuju analize slike 
žene u medijima u Srbiji ( van Zoonen 2004, Milivojević 2004, Višnjić, Mirosavljević 2008, Valić Nedeljković 2011, Filipović 2012.

Kada je reč o rodnoj perspektivi akademskog obrazovanja, pre svega na univerzitetima u Srbiji, postoje istraživanja koja se bave obrazovanjem žena (Popović 2004, Popović, Duhaček 2011) ali ona nisu usmerena na obrazovanje žena za pojedinačne profesije kao što je novinarstvo.

Prema Veljanovskom, potreba obrazovanja za novinarsku profesiju javila se već u 18.veku u Americi kao reakcija na komercijalizaciju medija i nepoštovanje javne etike. "Nastajanje standarda i pravila, kako profesionalnih, tako i etičkih, striktno vezanih za novinarstvo stvorilo je potrebu sistematske, interdisciplinarne edukacije novinara, koja se sa mnogo razloga u savremenom svetu obavlja na univerzitetskom nivou, mada se paralelno dešavaju i mnogi oblici alternativnog obrazovanja, koje uglavnom organizuju mediji, medijska udrženja i novinarska udruženja" (Veljanovski 2013:351-352). Podaci Fakulteta političkih nauka Univerziteta u Beogradu pokazuju da je za nešto više od četiri decenije (zaključno sa 30.9.2013. godine) novinarstvo diplomiralo 2.069 studentkinja (1.784 po starom sistemu i 285 po Bolonji) i 806 studenata. Prema evidenciji odbranjenih diplomskih radova na Odseku za medijske studije Filozofskog fakulteta u Novom Sadu, od 2008.godine, kada je studije završila prva četvorogodišnja generacija Žurnalistike do 25. oktobra 2013. godine novinarstvo je diplomiralo 110 studentkinja i 29 studenata. Kada je reč o formalnom obrazovanju zaposlenih u medijima istraživanje "Profesija na raskršću-novinarstvo na pragu informacionog društva 2010-2011." pokazuje da $39,61 \%$ novinarki ima završen fakultet, od čega $18,5 \%$ fakultet za novinarstvo, dok među muškarcima ima $30 \%$ onih koji su završili fakultet od čega je $12,69 \%$ završilo novinarstvo. Iako istraživanja pokazuju da su žene brojnije u novinarskoj profesiji i da su obrazovanije, one i dalje nemaju moć u medijima.

\section{OBRAZOVANJE I PROFESIONALNI STATUS NOVINARKI-ANALIZA REZULTATA ISTRAŽIVANJA}

\subsection{Formalno i neformalno obrazovanje}

Kako bi se kroz životne priče istražio uticaj formalnog i neformalnog obrazovanja na njihov profesionalni status i rodni identitet, novinarke su odabrane po nekom od četiri postavljena kriterija:

1. Novinarke koje su u novinarstvu više od dvadeset godina.

2.Novinarke za koje u društvenoj zajednici postoji konsezus medijskih profesionalki i profesionalaca, pripadnica i pripadnika intelekutalne elite da su ostvarile značajan profesionalan doprinos i ugled novinarstvu.

3. Novinarke koje su radile, odnosno rade u medijima, kako onima koji izveštavaju na srpskom tako i na manjinskim jezicima, koji imaju društveni uticaj u Vojvodini. 
4.Novinarke koje su dobile nagrade i društvena priznanja koje dodeljuju različite organizacije, institucije i novinarska udruženja u Vojvodini.

Uzimajući u obzir multietničku i multikulturalnu specifičnost Vojvodine za uzorak je odabrano osam novinarki, iz medija na jezicima različitih nacionalnih zajednica, kao i pripadnica većinskog naroda. Reč je o novinarkama različitog iskustva u profesionalnom radu, različitog uzrasta, sredine u kojoj žive, obrazovanja, vrste medija u kojem su radile ili rade (štampa, radio i televizija) i aktivizma u društvenom životu. Jedinica analize je odgovor na pitanja relevantna za temu istraživanja.

Kada je reč o početku bavljenja novinarstvom, jedna sagovornica I.H.K. (1944) novinarsku karijeru je započela šezdesetih godina prošlog veka, dve Ž.S. (1952) i Z.R. (1949) sedamdesetih, jedna osamdesetih, M.S. (1965), dve devedesetih B.D.S. (1973) i B.D. (1970) i dve su pripadnice mlađe generacije koje su počele posle 2000. godine I.S. (1977) i N.K. (1985). Što se tiče formalnog obrazovanja većina ima završen fakultet, najčešće Filozofski fakultet u Novom Sadu (I.H.K, Z.R. i I.S. završile su Književnost), B.D.S Pravni fakultet. Dve sagovornice (B.D. i N.K.) su završile Novinarstvo, na Fakultetu političkih nauka u Beogradu i Filozofskom u Novom Sadu i dve novinarke su upisale fakultet, Ž.S. Nemački jezik a M.S. Filozofiju ali ga nisu zavšile. Jedna novinarka B.D. je nakon osnovih studija magistrirala lingvistiku na Filozofskom fakultetu u Novom Sadu.

Novinarke koje su učestvovale $u$ istraživanju dobile su različite nagrade $i$ priznanja za svoj profesionalni rad, kao što su na primer nagrade vojvođanskih novinarskih udruženja (NDNV i DNV), medijskih kuća Dnevnik i RTV, festivala (Interfer) ili je reč o društvenim priznanjima za doprinos ostvarivanju rodne ravnoprannosti (Izvršno veće Vojvodine).

Imajući u vidu kontekst patrijarhalnog, agrarnog društva s početka 20. veka kada je svega $17 \%$ devojčica išlo u osnovnu školu dok je oko sedam odsto žena bilo pismeno, spram $15 \%$ pismenih muškaraca i činjenicu da se rodna ravnoteža u obrazovanju u tadašnjoj Jugoslaviji i Srbiji uspostavila tek posle Drugog svetskog rata (Popović 2014: 125-126), te da u prvim posleratnim godinama tekstove u novinama potpisuju aktivistkinje AFŽ-a, novinarke se u nešto većem broju pojavljuju tek šezdesetih godina. U skladu sa obrazovnom politikom koju je propagiralo socijalističko društvo i medijske kuće prepoznaju potrebu visokog obrazovanja zaposlenih te ih tih šezdesetih godina podstiču da završe fakultet o čemu svedoči i novinarka rusinskog nedeljnika Ruske slovo I.H.K. koja u novinarstvo ulazi tako što ta rusinska novinska izdavačka kuća traži da se na nju prenese dug stipendije zemljoradničke zadruge koja je obezbeđivala sredstva za srednju školu.

"Ja sam zaglavila u Ruskom Slovu i tako dvadeset dve godine [...] I onda su ljudi iz Ruskog Slova, koji su jako uticali i opredelili me da se bavim time s čime se celog života bavim i nije mi žao, govorili pa šta tu ti je Filozofski fakultet, tebe literatura interesuje nek se ekonomijom bavi onaj ko ima smisla za zarađivanje 
[...] I tako sam ja ostala u Ruskom Slovu i završila fakultet mogu da kažem baš u redovnom roku vanredno“(I.H.K. 1949).

Već sedamdesetih godina, ne presudan ali važan uslov za ulazak u novinarsku profesiju bio je završen fakultet o čemu govori i novinarka Z.R. koja se tada zapolsila u omladinskoj redakciji Radija Novi Sad:

"Dakle, ja sam '72. u januaru diplomirala. Uslov je bio da niko ne može bez diplome da se zaposli i moj urednik je sačekao da diplomiram i donesem radnu knjižicu. I to je redakcija u kojoj smo svi bili diplomirani. Naravno, samo je jedan kolega završio Fakultet političkih nauka u Beogradu, kasnije još jedan, a svi ostali smo bili sa Književnosti, Sociologije i ostalih društvenih nauka" (Z.R. 1949).

Krajem osamdesetih godina diploma nije bila odlučujući faktor za ulazak u novinarsku profesiju ali su ipak urednici nove, mlade novinare i novinarke tražili među studentima najčešće Filozofskog fakulteta, kao što je i slučaj M. S. koja je studirala Filozofiju u Beogradu:

„Gurala sam fakultet prilično nevoljno, stigla do četvrte godine, odnosno do samog kraja...u otporu i unutrašnjem nesaglanju, uz stalno lebdeće pitanje - šta ja tu uopšte ovde radim? Na sreću sam, tragajući za prostorom za sebe u Beogradu, na četvrtoj godini dobila priliku da uđem u redakciju NIN-a. Pokojni Ljuba Stojić, koji je bio jedan od urednika, tih godina je formirao istraživački centar u okviru $N I N$-a i mi smo tamo radili različita mala istraživanja na aktuelne društvene teme. Istraživački tim se popunjavao tako što je Ljuba s vremena na vreme dolazio na Filozofski fakultet i tragao za mladim ljudima koji bi želeli da rade"(M.S. 1965).

Političke promene krajem osamdesetih, nacionalistička ideologija i ratovi na teritoriji bivše Jugoslavije početkom devedesetih, dovode do devastacije svih sfera društva što se oseti u i obrazovnom sistemu. "Neformalno obazovanje se posmatra kao logičan odgovor na izrazito nepovoljne društvene okolnosti u kojima tradicionalni sistem formalnog obrazovanja ne može da zadovolji novonosastale obrazovne potrebe potrebe i pomogne prilagođavanju na promene" (Veselić, Popović 2008:331). Promene se reflektuju i u medijskoj sferi, gde, teorijsko fakultetsko obrazovanje postaje nedovoljno u odnosu na brzinu tehnoloških promena ali i načina prezentovanja medijskog sadržaja.

„Mislim da sam imala pet, šest predmeta koji su bili usko stručni, a ovo sve ostalo su bili politikološki predmeti. A i na tim stručnim predmetima malo šta se radilo praktično. Opšte siromaštvo u zemlji ogledalo se i na fakultetu. Nismo imali nikakvu opremu da bismo praktično radili vežbe iz stručnih predmeta. Nismo radili ni radijske, ni televizijske priloge, pisali smo samo tekstove. Snalazili smo se svako na svoj način kako ćemo doći do neke redakcije. Ja sam sa dvoje mojih kolega otišla na Radio202. Tada je 202 još uvek imala reputaciju važne „škole novinarstva" i bila je dosta slušana“" (B.D.1970).

Kao odgovor na nacionalističku i ratnu propaganda režimskih medija devedesetih godina se osnivaju privatni mediji finasirani od stranih donatora koji angažuju uglavnom mlade ljude bez obzira na njihov obrazovni status i profesionalno iskustvo. Nedostatak formalnog medijskog obrazovanja se 
nadoknađuje kursevima u novinarskim školama, gde su predavale iskusne novinarke i novinari.

"Pogotovo što smo mi među polaznicima imali najveći broj onih mladih ljudi koji su završili druge fakultete ne novinarstvo. Dakle istoriju, književnost, koji su se već negde muvali po medijima kako bih ja to rekla i koji su imali potrebu da steknu nešto i od znanja i od tog zanata. I oni su zapravo najviše i dobili, oni su najviše i napredovali u tom periodu kada smo najviše radili" (M.S. 1965).

"I onda ovaj sam videla neki oglas na Otvorenom univerzitetu novinarska škola koji je vodio Slobodan Budakov. On je nekad bio direktor $R T V$-a [...] Uglavnom završila sam tu novinarsku školu i onda me Budakov pitao da li bih radila negde" (B.D.S.1973).

„Međutim dok sam radila u tom butiku bilo mi je dosadno, pošto sam završila fakultet, i htela sam još negde da idem, još nešto da učim. Nemam normalan posao hoću još nešto. Ili nešto da studiram ili nešto da nadogradim znanje. I upisala sam Novosadsku novinarsku školu, oni su to zvali Specijalističkim studijama iz novinarstva. Ja to, ovako, realnije zovem kurs (I.S.1977)

Nakon društveno-političkih promena 2000. godine dolazi i do reforme visokoškolskog obrazovnog sistema, pa i obrazovanja novinara. Od sredine prve decenije 21.veka novinarstvo se u Srbiji studira na 12 fakulteta, sedam državnih i pet privatnih. Nov način studiranja, poznat kao Bolonjski proces, pokazuje tendenciju uravnotežavanja teorijskih i novinarsko-medijskih predmeta (Veljanovski 2013:357). Za razliku od devedesetih kada fakultetska diploma nije bila presudan faktor pri zapošljavanju novinarki i novinara, $u$ poslednjih desetak godina, bar što se tiče javnih medijskih servisa, visoko obrazovanje postaje formalan uslov za zasnivanje radnog odnosa

„Sećam se kada smo došli kako su nas ,prihvatili“ $i$ imali smo velikih problema da radimo na onaj način kako smo učili na fakultetu. Mi smo na fakultetu imali televizijsko novinarstvo gde smo jel upoznati sa tim $B B C$ standardima po kojima treba da se napravi jedan televizijski paket [...]Kada smo krenuli da ih radimo onako kako smo učili sa stendapom, sa odgovarajućim načinom izbora sinhrona i ostalo onda smo dobijali komentare kako se mi slikamo da bi nas videle babe i tetke i strine [...] I to je sve trajalo neko vreme dok se nisu pojavili ljudi iz $B B C$-ija koji su došli da drže seminare, edukaciju novinarima $R T V$-a. Ispostavilo se da smo na tim seminarima upravo mi znali već sve to što su oni pričali i da smo bili prilično aktivni. I da su se ljudi oduševili i rekli odakle ste vi došli?"“(N.K.1985).

\subsection{Rodna ravnopravnost u redakcijama}

Novinarka I. H. K. bila je jedina žena u redakciji Ruskog slova 1964. godine kada je počela da se bavi novinarstvom.

"Pa tada sam bila jedina, valjda mi je zato i bilo lepo. Ja sam bila mlada oni svi već, mislila sam, čike matore. Ja sam se samo smejala a njima se valjda sviđalo 
što sam oduševljena njima. Svi to vole [...] I bila je jedna koleginica na rusinskom na radiju" (I.H.K. 1944).

Sedamdesetih godina veći je broj žena u medijima, međutim upravljačke strukture su i dalje prepuštene muškarcima

„Kad sam došla u Radio Novi Sad mislim da su svi urednici resora bili muškarci. Žene su se „probijale“ kasnije u emisijama za kulturu i gradskim rubrikama, ali se dobro sećam da je isticano kako Radio Novi Sad ima ,jako dobrog ženskog skupštinskog izveštača“ [...] U redakcijama se „rodna razlika“ nije osećala. Nije bila eksplicitna ni u odnosima urednika i novinara na toj osnovi, ali je menadžment, rukovodstvo medijsko, uglavnom bilo muško. Kad danas razmišljam o tome, padne mi napamet da među vlasnicima medija ne znam mnogo ili tek koju ženu“" (Z.R. 1949).

Bez obzira na veći broj žena u novinarstvu, osamdesetih godina pojedini renomirani informativno-politički mediji, poput nedeljnika $N I N$ i dalje teže otvaraju vrata novinarkama.

"E to je zanimljivo, nije bilo novinarki u redakciji. Bile smo samo mi koje smo bile deo Ljubinog tima [...] Mi nekako nismo ni imali prilike da se previše mešamo sa njima. Znalo se u kojoj kafani oni sede. Ko u tom miljeu može da bude. Dakle mi smo bili previše nevažni s tom razlikom što sam ja uvek imala malo tu drčnost i imala sam potrebu da se ponekad upuštam u diskusije"(M.S 1965).

S povećanjem broja žena u novinarstvu, dolazi do polne podele podele poslova i rubrika, te se izveštavanje o kulturi često smatra ženskom, dok sport važi za isključivo mušku oblast.

„Na primer, u kulturi su uvek kod nas radile žene. Ali to je nekako i očekivano. Žena će se pre latiti kulture u novinarstvu nego muškarac; mali je broj njih. Na primer bilo bi mi jako čudno da na čelu sportske redakcije bude žena. To bi već bilo, nekako, revolucionarno. Nismo nikad ni imali ženu novinarku u sportskoj redakciji“" (I. S. 1977).

Većina sagovornica nema lično iskustvo neravnopravnog položaja u odnosu na muške kolege, međutim smatra da je ženama ipak teže da opstanu i postignu uspeh u novinarskoj karijeri.

„Dešavalo se da se novinarkama prebacuje „prekomerno“ bolovanje ili da se posle porođajnog odsustva ne vrate na svoje, nego, „niže“ radno mesto, ne po plati, već po profesionalnom angažmanu“"(Z.R. 1949).

„Śto se tiče posla tu jesam povremeno osećala razliku. Na novinarke se generalno gledalo kao na manje vrednu vrstu. Biti novinarka, značilo je biti alapača, biti gruba, nadrkana..." (B.D 1970)

"Nikad nisam osetila uopšte problem to što sam ja sad kao žena. Nemam uopšte tih nekih iskustava u tom smislu" (B.D.S.1973).

„S obzirom na to, da ako se potpuno predaš ovom poslu nije lako biti žena $u$ novinarstvu, jer ti tu imaš vrlo malo vremena za privatni život. Uostalom, teško se i udaju žene u novinarstvu. Evo, ovi kod mene u Radio Novom Sadu, obično se 
nađu tu na poslu muž i žena. Pa onda imaju iste i priče i taj posao nose kući. To je posao sa kojim živiš“ (I.S. 1977).

\subsection{Rodno osetljiv jezik u medijima}

Jedan od osnovih pokazatelja ravnopravnog položaja žene u društvu jeste upotreba rodno osetljivog jezika u javnom govoru. "Rodno osetljiv jezik je termin kojim se pokazuje težnja da jezik pomogne u ostvarivanju ljudskih prava kad su u pitanju ženske ili muške osobe. Ovo je samo deo ukupne problematike koji zovemo politički korektan govor/jezik, usaglašen sa zahtevima datim u Deklaraciji o ljudskim pravima: niko ne sme biti diskriminisan pomoću jezika“" (Savić 2009, 7). Novinarke iz starijih generacija koje su karijeru počele sedamdesetih godina uglavnom za sebe kažu da su novinari a ne novinarke, međutim generalno nemaju ništa protiv upotrebe rodno osetljivog jezika.

"Ja sam u profesiju ušla kao novinar i tako je završila. I ne zvuči mi to ni arhaično ni manje vrednovano. Ali, sada, kada govorim o svojim koleginicama iz prošlosti, govorim kao o novinarkama, kao što za žene koje se danas bave tom profesijom, kažem da su novinarke“ (Z.R. 1949).

"Postignut je veliki napredak, naravno, ne koriste ga svi mediji, ali makar smo stigli dotle da se u medijima trudimo ali opet mislim da nije kodirano u smislu kodeksa i obaveznog ponašanja i pisanja u redakcijama i bojim se da je to još uvek u velikoj meri prepušteno ličnom stavu ili osećaju ili svesti samog novinara ili novinarke" (Ž.S. 1953).

Rusinski jezik je specifičan kada je reč o ženskom rodu:

„Baš sam razmišljala na tu temu i meni se čini da rusinski jezik više čuva tu rodnu senzitivnost. Nikad ne bih rekla recimo da je Marija, ne znam, Malackov profesor tog jezika nego profesorka. Tako, recimo, rusinski žerna nikad nije dečiji lekar nego lekarka“" (I.H.K. 1944)

Novinarke mlađe generacije koriste rodno osetljiv jezik ali ne sasvim dosledno.

„Ja sam ga, donekle, koristila i pre nego što smo doneli odluku o tome u Radio Novom Sadu, ali, ipak, postoje reči koje ne možemo upodobiti. Na primer, sudinica, sutkinja meni je to potpuno besmisleno da kažem. I reći ću sudija za ženu. Ili advokat. Ne znam kako da kažem- advokatica? Kada se kolebam, uvek konsultujem sa lektorkom. Poštujem rodnu ravnopravnost, kada je reč o jeziku, gde god je to moguće“"(I.S.1977).

Generalno novinarke koje su obuhvaćene istraživanjem su svesne značaja upotrebe rodno senzitivnog jezika, što može biti i rezultat različitih seminara, edukacija i kampanja organizovanih od strane ženskih nevladinih organizacija ili od strane pokrajinskih instiucija Zavoda za rodnu radnopravnost Vojvodine i Pokrajinskog zaštitnika građana-ombusmana.

„Gledano sa stanovišta prihvatanja „ponude“ koju je dala grupacija ženskih nevladinih organizacija kroz Kodeks rodno senzitivnog izveštavanja, mi i dalje nemamo veliki broj medija koji su spremni i otvoreni za promene. Kodeks je 
potpisalo i primenjuje dvadesetak medija u celoj Srbiji (uključujući nacionalni, pokrajinski i lokalni nivo). Ono što je dobro, to je da je $B 92$ kao medij sa nacionalnim pokrivanjem, prihvatio inicijativu i vrlo dosledno koristi rodno osetljivi jezik. Ne besprekorno, ali svakako dosledno. Sa druge strane ta praksa nije uvedena u javnom servisu, i to nije dobro“" (M.S.1965).

\subsection{Profesionalni/rodni identitet novinarki}

Istraživanje je pokazalo da je kod svih sagovornica jasno izražen profesionalni identitet, one su ostvarene u svojoj karijeri o čemu svedoče i nagrade koje su dobile i nijedna nije zažalila što je ušla u svet novinarstva.

“Ono što je važno to je da je nagrada od kolega, nagrada za „doprinos demokratizaciji“, koja je zbilja potpuno iznenađenje, bila je to povodom jubileja Nezavisnog društva novinara Vojvodine i upravo zbog te geneze u kojim sam medijima radila to mi baš znači, bez obzira na neke druge gubitke na drugim planovima ili uskraćenostima, nije mi ničeg žao. Ne stidim se nijedne rečenice, stojim iza svake koju sam napisala - a šta ćeš više u našoj profesiji? U burnim vremenima, a i dalje su burna" (Ž.S.1953).

„Imala sam milion stresnih, užasnih situacija, navikla sam da tako funkcionišem. To mi još dođe kao podstrek, probudi inat" (B.D.S. 1973).

Možda zbog toga što sam inače više volela da se družim sa dečacima. Mislim volela sam i sa devojčicama, ali naši razgovori su se uvek svodili na kokošinjac, kad sve u glas grakćemo i vrišteći pričamo o dečacima i nekim budalaštinama. [...] Bila sam uvek odgovorna i baš posvećena poslu. I uvek sam po tome računala, ja sam $24 \mathrm{~h}$ novinar, prihvatala sam i da me u dva, tri, šest ujutro bude jer je to bio moj posao, moje opredelenje" (B.D. 1970).

Novinarke koje su učestvovale $u$ istraživanju zalažu se za rodnu ravnopravnost u društvu, što je sa uopštenim zalaganjem za poštovanje svih ljudskih prava u skladu sa etikom profesije. Međutim, izraženost ličnog rodnog identiteta zavisi od ostvarenosti patrijarhalno postavljenih uloga žene kao majke i supruge.

"Ja radim svoj posao i hoću da to pošteno odradim, ali mislim, sad ću reći neku jeretičku misao, da su žene same sebi najveći neprijatelji. One pristaju i češće su žene, jer muškarce je baš briga u suštini, pokušavale da mi nametnu a ja sam, moram biti iskrena nasedala, kompeticiju u oblastima koje su tipično ženske "(I.H.K. 1944).

Ostvarenjem tradicionalnih ženskih uloga trpi profesionalna novinarska karijera jer zbog porodičnih obaveza ne mogu da ispune sve zadatke, štu ukazuje na koliziju, pa čak i na međusobno isključivanje rodnog i profesionalnog identiteta.

„Ja nisam imala iskustvo da me neko manje poštuje zbog toga što sam žensko, nikada. Druga stvar je socijalna pre svega iz razloga što je ženama teže onog trenutka kada dobiju decu, ja mislim da se promene i njihovi prioriteti. Posao negde dolazi na drugo, treće, peto mesto. Sa drugačijim žarom pristupaju poslu. To se oseti na kvalitetu toga što rade i samim tim onda se možda urušava taj njihov 
ugled u redakciji koji su ranije stekle ili ih prosto ljudi drugačije doživljavaju kao nekog ko baš i neće moći svoje zadatke da ispuni“ (N.K. 1985).

Bez obzira na uspeh u novinarskoj karijeri i materijalnu sigurnost, samovrednovanje profesionalne ostvarenosti, na šta ukazuje svedočenje novinarke I.S, je vrlo nisko izraženo jer se očekuje i traži muška potvrda životnog uspeha žene.

„Kada govorimo o stepenu emancipacije u našoj zemlji, ovo je super što ja imam. Ali je zato s druge strane meni teško da nađem muškarca, na primer. Jer muškarci se plaše emancipovanih žena. Muškarci se povlače pred takvim ženama. Bila sam za emancipaciju žene, oduvek. Sad se pitam šta je dobro donela ta emancipacija? Žena mora da shvati, ok, imam to i to a sad moram u nekim segmentima života da spuštam rogove, ne mogu sad u svemu da budem prva i da imam mišljenje o svemu i da budem najbolja. Muškarcima treba ostaviti prostor za delovanje. Emancipovanoj ženi je potreban jak, stabilan muškarac koji nije iskomplekiran“"(I.S. 1977).

\section{ZAKLJUČAK}

Analiza usmenih životnih priča (oral history) osam novinarki iz Vojvodine, kojom je obuhvaćen period od prve polovine šezdesetih godina 20.veka pa do kraja prve dekade 21.veka, pokazala je da je za bavljenje novinarstvom bitno visoko obrazovanje ali i da je za uspeh u profesionalnoj karijeri i društveno priznanje značajno neformalno obrazovanje u smislu celoživotnog učenja. Sećanja novinarki pripadnica starijih generacija koje su karijeru počele šezdesetih i sedamdesetih godina pokazuju da je tadašnja socijalistička Jugoslavija podsticala visoko obrazovanje žena, što je prihvaćeno i od strane medijskih kuća u vidu stipendija (Ruske Slovo, RTV Novi Sad). Društveno-političku krizu i ratove devedesetih godina pratila je i degradacija formalnog obrazovnog sistema, što dovodi do masovnije pojave različitih oblika neformalnog obrazovanja, koje se u medijskom svetu organizuje kroz kurseve u novinarskim školama. Reformom sistema vioskog obrazovanja posle 2000. godine fakultetska diploma ponovo postaje jedan od bitnih uslova za zaposlenje u ozbiljnim medijskim kućama, kao što su javni servisi.

Istraživanje je potvrdilo pretpostavku da formalno akademsko obrazovanje ima značajan uticaj na kvalitetan profesionalni rad novinarki, ali nedovoljno za rodno osetljiv pristup. Sve novinarke se načelno zalažu za upotrebu rodno osetljivog jezika u javnom govoru, međutim ne koriste ga sasvim dosledno, a pojedine kada govore o sebi koriste muški rod "novinar". U tom smislu mogla bi se napraviti paralela između doslednosti upotrebe rodno senzitivnog jezika i pohađanja seminara o rodnoj ravnopravnosti organizovanih od strane ženskih organizacija koje su pohađale pojedine novinarke. Istraživanje je pokazalo i da je kod svih sagovornica jasno izražen profesionalni identitet o čemu svedoče i nagrade i društvena prizanja. Novinarke smatraju da se generalno žene nalaze $u$ 
neravnopravnijem položaju u odnosu na kolege novinare, pogotovo kada je reč o upravljačkim funkcijama gde su i dalje muškarci u većini. Međutim govoreći o ličnim iskustvima sagovornice uglavnom negiraju probleme ili mogućnost da je njihov rad manje vrednovan zato što su žene. Analiza pokazuje međusobno potiskivanje, pa i isključivanje rodnog i profesionalnog identiteta jer se pretpostavlja da jedan deo mora da „trpi“ u slučaju kada novinarka ostvari tradicionalno postavljene ženske uloge-postane majka i supruga. U tom slučaju postavlja se relacija posao ili porodica, što za većinu muškaraca u novinarstvu nikad nije ključno pitanje. Takođe se može konstatovati i da kod jako izraženog profesionalnog identiteta novinarki, dolazi do negacije rodnog identiteta, jer se ulaže dvostruki napor da se ispune ženske obaveze a potom minimalizuje njihov značaj da bi se pokazalo da se može dostići uspeh muškaraca u novinarstvu.

\section{LITERATURA}

Batler, Dž. (2010). Nevolja sa rodom: feminizam i subverzija identiteta. Loznica: Karpos.

Bahovec, E. (2011). Egzistencijalistički feminizam. Uvod u rodne teorije.Novi Sad: Mediterran publishing.

Blagojević, J, Lončarević, K. (2011). Posmoderni feminizam. Uvod u rodne teorije.Novi Sad: Mediterran publishing.

De Berg, H. (2007). Istraživačko novinarstvo. Beograd: Klio.

De Bovoar, S. (1982). Drugi pol II . Beograd: Bigz.

Derida, Ž. (2000). Koreografije. Ženske studije, 11/12 . Beograd: Centar za ženske studije.

Gill, R. (2007). Gender and the Media. Cambridge: Polity Press.

Matović, M. (2012). Novinarstvo i medijska industrija u Srbiji: borba za očuvanje profesionalizma. U CM: časopis za upravljanje komuniciranjem 24. (str. 133-150). Beograd:Fakultet političkih nauka.

Matović, M. (2013). Rodna dimenzija novinarske profesije u Srbiji. Genero. (str. 97-118). Beograd: Ženske studije

Milivojević, S. (2004). Žene i mediji: Strategija isključivanja. Žene, mediji, rod, identitet. Genero, 4-5. (str.11-24). Beograd: Ženske studije.

Milivojevic, S. (2011). Profesija na raskršcu - novinarstvo na pragu informacionog društva. Beograd:Fakultet politickih nauka. Preuzeto 20. novembra 2014. sa http://www.fpn.bg. ac.rs/2011/07/14/profesija-na-raskrscu

Popović, D, Duhaček, N. (2011). Obrazovanje. Uvod u rodne teorije.Novi Sad: Mediterran publishing.

Popović, D. (2014). Naučna pismenost kao pokazatelj rodne diskriminacije“. U Obrazovanje, rod, građanski status (str. 115-130). Beograd: Fakultet političkih nauka:

Savić, S. (2001), Vojvođanke (1917 - 1931): životne priče. Novi Sad: Futura publikacije i Ženske studije i istraživanja.

Savić, S, Čanak, M, Mitro,V , Štasni, G. (2009). Rod i jezik. Novi Sad: Ženske studije i istraživanja i Futura Publikacije.

Stojaković, G. (2012). Rodna perspektiva u novinama Antifašističkog fronta žena (1945-1953). Novi Sad: Zavod za ravnopravnost polova. 
Tomić, S. (2014). Obrazovanje i osvajanje građanskog statusa žena: prve srpske učiteljiceknjiževnice. U Obrazovanje, rod, građanski status (str. 38-56). Beograd: Fakultet političkih nauka.

Trgovčević, Lj. (2014). Počeci višeg obrazovanjadevojaka u svetu i kod nas. U Obrazovanje, rod, građanski status (str. 57-68). Beograd: Fakultet političkih nauka.

Valić-Nedeljković D. (2011). "Rod i mediji”. Uvod u rodne teorije (str.447-459).Novi Sad: Mediterran publishing.

Van Zoonen, L. (1994). Feminist Media Studies. London: Sage.

Velčić, M. (1991). Otisak priče. Zagreb: August Cesarec.

Veljanovski , R. (2013). Obrazovanje novinara između tehnološkog determinizma i sistema vrednosti. U Valić-Nedeljković,Pralica (ured) (2013). Digitalne medijske tehnologije $i$ društveno-obrazovne promene 3 (str.351-359). Novi Sad: Filozofski fakultet.

Veselić B, Popović K. (2008). Društvene promene I neformalno obrazovanje žena u Srbiji i hrvatskoj devedesetih godina XX veka. U Andragoške studije (str. 331-343). Beograd: Filozofski fakultet.

Vilenica, A. (2013). Postajanje majkom u vreme neoliberalnog kapitalizma. Beograd: Uzbuna, Novi Sad: Daniel Print.

Zaharijević A, Lončarević, K. (2008) "Kratki istorijski pregled važnijih datuma za femnizam u Srbiji i svetu”. Neko je rekao feminizam. Beograd: Heinrich Böll Stiftung.

\title{
SOCIAL CHANGES AND EDUCATION- PROFESSIONAL AND GENDER IDENTITY JOURNALIST IN VOJVODINA
}

\begin{abstract}
SUMMARY
Formal academic education has a significant impact on the quality professional work of journalists, but not enough for gender-sensitive approach, the basic conclusion of the research. The importance of non-formal education is of great importance the last two decades when it comes to technological progress which is reflected most precisely in the media, through the process of digitizing and creating new distribution platforms of media content. The survey was conducted by the method of oral life stories (oral history), which is one of the possible ways of recording, analyzing and interpreting the experience of women as a testimony to the social circumstances in a given period of time. For sample consisted of eight journalists from media reporting in the languages of different ethnic communities, different professional experience and social activism. The idea of this work was to demonstrate how the formal and informal education affects the formation of the professional identity of the journalist, the correlation of professional and gender identity, and how education can contribute to a more equal position of women in society.
\end{abstract}

Key words: education, journalist, gender identity, professional identity, social change. 